\title{
Safety in numbers: lack of evidence to indicate the number of physicians needed to provide safe acute medical care
}

\author{
Authors: Jodie Sabin, ${ }^{A}$ Christian P Subbe, ${ }^{\mathrm{B}}$ Louella Vaughan ${ }^{\mathrm{C}}$ and Rhid Dowdle ${ }^{\mathrm{D}}$
}

\begin{abstract}
Patient safety in hospital is dependent on a multitude of factors. Recent reports into the failings of healthcare organisations in the UK have highlighted low staffing levels as a significant factor. There is research into the impact of nurse-to-patient ratios on patient safety, but our literature search found little published data that would allow healthcare providers to define a minimum number of physician staff and skills mix that would assure safety in the largest hospital specialty: unscheduled (acute) medicine. Future work should focus on the evaluation of existing data on hospital mortality rates and physician staffing levels as well as on empirical time and motion studies to ascertain the resources required to undertake safe medical care at times of peak demand.
\end{abstract}

KEYWORDS: Mortality, personnel staffing and scheduling, workload, patient safety

\section{Background}

The political context

Safe staffing levels in acute care is a subject of intense debate, particularly since the Francis report identified inadequate staffing levels as one of the key factors that led to poor quality care at Mid Staffordshire NHS Trust. ${ }^{1}$ The Review into the quality care and treatment provided by 14 hospital trusts in England, led by Sir Bruce Keogh, similarly pointed to the impact of workforce issues on hospital mortality, with inadequate levels of available staff, a reliance on locum or temporary staff and the poor provision of weekend and night cover being key issues. ${ }^{2}$ The report particularly emphasises the difficulties in adequately supporting frontline nurses and junior doctors, who shoulder the main burden of acute and emergency care.

Authors: ${ }^{A}$ academic fellow, Department of Medicine, Ysbyty Gwynedd, Bangor, UK; ${ }^{B}$ Consultant physician, Department of Medicine, Ysbyty Gwynedd, Bangor, UK; ${ }^{C}$ Acute Theme Care lead, Department of Medicine, Northwest London Collaboration for Leadership in Applied

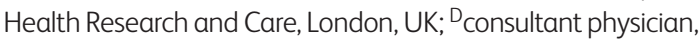
Department of Medicine, Royal Glamorgan Hospital, Llantrisant, UK
One of Francis' recommendations was that there should be evidence-based tools for establishing the staffing needs of each service. ${ }^{1}$ The report into patients' safety commissioned by the Department of Health and undertaken by Don Berwick also recommended that organisations should ensure that staff are available in appropriate numbers to provide safe care and suggested a NICE review into staffing numbers. ${ }^{3}$ Currently, there is very little guidance regarding safe physician staffing levels in acute medical care.

\section{Current recommendations}

The Royal College of Physicians (RCP) recommends that there should be consultant presence on the acute medical unit (AMU) for a minimum of 12 hours per day, 7 days per week. ${ }^{4,5}$ The number of consultants involved daily on the AMU should reflect pro rata the number of patients expected to attend. ${ }^{6}$ In the 2010 edition of its document Consultant physicians working with patients: acute internal and general internal medicine, the RCP recommended that a foundation or core medical training (CMT) doctor should be allowed 1 hour to complete the formal assessment of a patient presenting to hospital with an acute medical problem. This recommendation was extended to 1.5 hours in the 2013 edition of the same document, based on anecdotal evidence alone. ${ }^{5}$

We aimed to explore the existing literature for optimum physician staffing levels relating to acute (internal) medicine.

\section{Methods}

\section{Search strategy}

Terms derived from a preliminary review of the problem were mapped against MESH terms and searched on Medline using Ovid and Embase. Additionally, terms were explored using Google, both in the Scholar and the general section. References of publications identified were searched for further documents. Search terms used were: physicians, workload, hospital mortality, personnel and staffing, scheduling, quality of health care, patient safety and patient admissions.

If processes described in emergency department (ED) studies were comparable to those pertaining to acute medicine, these studies were included. 


\section{Exclusions}

There is already a considerable body of evidence around the relationship between staffing levels of nurses and clinical outcomes $^{7-10}$ and the effect of working hours on staff performance leading to national and international policy decisions. ${ }^{1-13}$ We therefore excluded studies focused on these two areas.

\section{Results}

Our search uncovered a very limited number of relevant papers (Table 1). The number of physicians required to look after emergency admissions to a medical department will depend on patient, hospital, team and physician characteristics. ${ }^{14}$ This review focuses on four (admittedly overlapping) themes:

$>$ workload and quality of care

$>$ what takes the time (ie time and motions studies)

$>$ patient complexity and the time required for care

$>$ service design and skill mix.

\section{Workload and quality of care}

There is a perception that high workload results in poor quality of care. In 2012, the RCP found that $37 \%$ of trainees assessed the workload of a medical registrar as unacceptable..$^{15}$ Similarly, in a cohort of 506 hospital consultants in the USA, 40\% reported that their typical inpatient load exceeded safe levels at least monthly, with 15 patients per day being the maximum number felt to be safe. Workload prevented doctors from fully discussing care with their patients and families, delayed discharges and affected the quality of handovers. ${ }^{16}$ Both studies noted the negative impact of increased patient numbers and staffing shortages.

The relationship between workload and measurable outcomes is less clear. In the UK, Bell et al found that hospitals with more than 40 admissions per day had reduced case fatality rates $(\mathrm{p} \leq 0.03)$ but that patients on a high admission day had a longer mean length of stay $(\mathrm{p} \leq 0.02){ }^{16}$

Conway et al analysed consultant admission numbers over a 10 -year period in the UK. They found that patients admitted to consultants with the highest volume of admissions had shortened lengths of stay $(\mathrm{p}<0.001)$ and reduced 30-day in-hospital mortality $(\mathrm{p}<0.1)$ when compared to consultants with lower volume of admissions, suggesting that more practice does result in improved patient outcomes. ${ }^{17}$

In the USA, Mueller et al found that increasing resident workload, measured by average patient numbers, resulted in nonsignificant reductions in the quality of treatment for pneumonia, acute myocardial infarction and congestive cardiac failure. ${ }^{18} \mathrm{~A}$ retrospective analysis of 12,119 US admissions showed that the busiest teams had a $21 \%$ increase in 30 -day re-admissions, albeit with no significant effect on 60 -day mortality rates. ${ }^{19}$ In a separate study, capping of the maximum number of patients at 14 per resident led to a non-significant decrease in patient readmission rates $(\mathrm{p}=0.04)$. Other patient safety indicators did not change but resident's attendance at teaching improved. ${ }^{20}$

Researchers in San Francisco found that after adjusting for case-mix in a cohort of 5,742 patients, mortality rates increased in teams that had more than nine admissions per team daily. Patients admitted on a day with a high admission rate also had an increased length of stay. ${ }^{21}$
Haney et al describe a parabolic curve for workload vs learning. As the number of cases increases, so does learning, but there is a maximum point above which learning decreases. ${ }^{22}$ Thus, although there is evidence that 'busyness' decreases opportunities for formal teaching, this may be compensated by the learning acquired from seeing patients.

\section{What takes the time?}

Herring et al found that reviews of patients in an English hospital during consultant-led rounds averaged 10 minutes on routine rounds and 14 minutes on post-take ward rounds, with a range of 8 to 24 minutes. ${ }^{23}$ An American study similarly noted a median time of 13 minutes per patient on consultant rounds. ${ }^{24}$ Multiple factors were noted as impacting on the length of consultant rounds, including the seniority of the consultant physician ${ }^{25}$ and the presence of students on the round. ${ }^{24}$

A systematic review of time-and-motion studies evaluating the working hours of hospital physicians was unable to summarise findings because of lack of methodological standardisation and differing activity categorisation between the studies. However, activities relating indirectly to a patient's care (eg documentation and communication with other professionals) took consistently more of the hospital physicians' time than direct interaction with patients, the latter averaging only $23 \%$ of physicians' working day. ${ }^{26}$ Physicians working in an acute medical admissions department in Denmark spent an average of 45 minutes on the admission process, of which 15 minutes were spent interviewing and examining the patient and 13 minutes were spent on interruptions. ${ }^{27}$ Similarly doctors in Germany were interrupted an average of 3.7 times per hour. There was a significant association between overall interruptions and doctors self-reported workload ratings. ${ }^{28}$ The combination of interruptions and multiple tasks may produce clinical errors by disrupting memory processe ${ }^{29}$ and increasing cognitive workload with loss of attention on the original task. ${ }^{30}$

\section{Patient complexity}

The difficulty in determining optimum ED staffing shows analogies to the problems faced in acute medicine. Analysis of 585 patient encounters in an ED in Vancouver found that the strongest identifiers for physician workload (defined as the time spent with each patient) were: need for a procedure, triage level, arrival by ambulance, Glasgow Coma Score (GCS), age, comorbidity and number of prior visits to hospital. ${ }^{31}$ Care for frail elderly patients with multiple comorbidities requires a significant amount of time that is not necessarily reflected in triage categories that are based on acuity scores. A study of 11,716 Canadian ED patients showed significant variability in physician time relating to each triage category, even after adjustment for case-mix. ${ }^{32} \mathrm{~A}$ literature review of staffing models based on triage categories used in Canada found that none of the current models could be relied upon to accurately predict staffing levels. ${ }^{33}$

\section{Service design and skill mix}

In the study by Bell et al, a national survey of consultant working patterns was linked to data from 1.3 million patients and to hospital-episode statistics. Consultant presence in the AMU 
Table 1. Themes from literature review and country of origin.

Article

\section{Workload}

Developing a model for attending physician workload ${ }^{14}$

The medical registrar: empowering the unsung heroes of patient care ${ }^{15}$

Impact of attending physician workload on patient care: a survey of hospitalists 43

Impact of resident workload and handoff training on patient outcomes ${ }^{18}$

The effect of the number of admissions to inpatient medical teaching team on patient safety outcomes ${ }^{19}$

Service census caps and unit based admissions: resident workload, conference attendances, duty hour compliance and patient safety ${ }^{20}$

House staff team workload and organisation effects on patient outcomes in an academic general internal medicine inpatient service ${ }^{21}$

Relationship between resident workload and self-perceived learning on inpatient medicine wards 22

A method for assessing house staff workload as a function of length of stay ${ }^{39}$

\section{Timing of processes}

Quality and safety at the point of care: how long should a ward round take?23

Attending ward rounds in the current era: what is and is not happening 24

No substitute for experience: do consultants that have been practising for longer lead faster post-take medical ward rounds?25

Systematic review of time studies evaluating physicians in hospital setting ${ }^{26}$

Hospital admission interviews are time-consuming with several interruptions ${ }^{27}$

Association of workflow interruptions and hospital doctors' workload: a prospective observational study ${ }^{28}$

The multi-tasking clinician: decision making and cognitive demand during and after team handoffs in emergency care $^{30}$

\section{Patient complexity}

Prospective time study derivation of emergency physician workload predictors ${ }^{31}$

Physician workload and the Canadian emergency department triage and acuity scale: the predictors of workload in the emergency room (POWER) study ${ }^{33}$

Emergency physician workload modelling

\section{Service set up and skill mix}

Consultant input in acute medical admissions and patient outcomes in hospitals in England ${ }^{17}$ Consultant volume, as an outcome determinant, in emergency medical admissions ${ }^{18}$

The value of the post-take ward round: are new working patterns compromising junior doctor education? ${ }^{36}$ Reduced productivity among junior trainees in the emergency department and the impact on senior clinicians ${ }^{37}$

Senior house officers and foundation year doctors in emergency medicine: do they perform equally? ${ }^{38}$

Patient need at the heart of workforce planning: the use of supply and demand analysis in a large teaching hospital's acute medical unit ${ }^{39}$

\section{Country}

Year of publication

USA

2013

UK

USA

2013

USA

2012

USA

USA

2012

USA

USA

2006

USA

UK

2011

USA

UK

Multiple countries

2010

Denmark

2012

Germany

2012

USA

Canada

2005

Canada

2009

Canada

UK

2013

UK

UK

UK

2010

UK

2008

UK for a minimum of 4 hours per day was significantly associated with reduced adjusted hospital mortality $(\mathrm{p}<0.01)$ and 28 -day readmission rates $(\mathrm{p}<0.01) .{ }^{16}$ Furthermore, eight out of the 12 hospitals with the lowest hospital standardised mortality rates (HSMR) in 2012 were in London, the area with the highest ratio of consultants per patient in England. ${ }^{34}$ Consultant presence will additionally impact on junior doctors' experience. ${ }^{35}$ A Scottish study found a statistically significant reduction in the mean number of patients seen per hour by junior doctors after the introduction of the Foundation Training programme in 2006 $(\mathrm{p}=0.033) .{ }^{36}$ The same centre also demonstrated that junior doctors perform significantly better in the last month of their ED placement than in the first $(\mathrm{p}=0.004) .{ }^{37}$

Researchers from Nottingham found that high patient-per-doctor ratios from early evening until midnight resulted in large numbers of acute medical patients waiting to be seen. Altered shift times to 
meet patient demand led to improved performance. ${ }^{38}$ A US cancer centre found that although the total number of occupied beds per doctor in the hospital decreased over a 3-year period, this was due to higher turnover of patients. They concluded that absolute patient numbers at any one time was not the most appropriate way to assign medical staff to units and consideration needed to be given to the additional work that admission- and discharge-related processes generate. ${ }^{39}$

\section{Discussion}

\section{General considerations and limitations}

Our search identified only a few studies that have examined the relationship between work generated by admissions, patient outcomes and physician staffing levels. Given the international concerns about the future and affordability of hospital medicine and the interest in patient safety, the paucity of epidemiological and interventional studies into this association is surprising.

\section{Workload}

Increasing workload leads to a perception that quality of care is reduced, but there is conflicting evidence when comparing the number of admissions to measurable outcomes. Part of the difficulty in this comes with defining how workload is measured and what exactly it means to be responsible for ' $x$ ' number of patients.

There is also little consideration of work generated outside of the admissions process, such as involvement with the hospitalat-night teams, need for cross-covering wards, referrals from other specialties and attendance at cardiac arrests. All of these will have an additional impact on doctors' workload and will vary between hospitals and with local service set-up. It is possible that data on workload are published outside the medical literature in publications on ergonomics or finances. We have not, however, identified pointers to this direction from a cursory review of hits as part of our search on Google.

\section{Timing of processes}

Activities relating to indirect patient care frequently take up the majority of physicians' time, regardless of where they work. It is important to note that the timing of processes does not necessarily correlate directly with quality. Junior doctors need to be given adequate time, learning opportunities and supervision to ensure they are receiving the high-quality training needed to prepare them to be future senior doctors.

\section{Patient complexity}

The general feeling is that simple measures, such as number of presentations, are insufficient to predict staffing needs. Models need to take into account variables such as patient complexity and acuity. This has significant implications for weekend working, as there is increasing evidence that although fewer patients present on the weekend, many are sicker and have more complex needs.

\section{Service set-up and skill mix}

The skills-mix of whole teams must be taken into account. Although there is guidance regarding consultant numbers (which is based on little or no evidence), there are even more limited data regarding the number of foundation doctors, senior house officers and middle-grade doctors, and the rapidly rising number of advanced nurse practitioners needed, even though the wards also depend heavily upon them.

Internationally, there has been a move to mandate nursing staffing levels in California, USA and Victoria, Australia based on evidence that nurse staffing levels were directly related to mortality rates. ${ }^{7}$ As yet no country has introduced mandatory physician staffing levels.

\section{Limitations}

Our study has significant limitations. The small number of articles we found are mostly the work from single centres or from the USA, with its vastly different team structures, roles and responsibilities. Nevertheless, some common themes do emerge despite the different systems. The NHS has undergone major changes in recent times including the introduction of the European Working Time Directive in 2003, which limits junior doctors to a 48 -hour working week. In addition, significant changes to training programmes were brought about by the Modernising Medical Careers initiative in 2005 . These changes have produced a major shift in service delivery and workloads in the UK during the past few years, making the interpretation of the scarce literature even more difficult. We see this as a strong driver to promote contemporary research into service delivery in the UK.

\section{The way forward}

In order to assure a more rational approach to safe staffing levels, a number of approaches might be needed.

1 Existing databases of hospital activity should identify those hospitals with best outcome data. Their staffing levels for unscheduled care could be examined and contrasted with those of hospitals with worse outcomes.

2 The Society for Acute Medicine's Benchmarking Audit (SAMBA, 2013) contains data on case mix, including severity of illness as measured by the National Early Warning Score (NEWS), an index for dependency of patients and some data on staffing levels of AMUs. It might be possible to derive from these data averages and outliers with regards to staffing.

3 Observational work of doctors' engagement with emergency admissions and hospital-wide referrals is required to determine which parts of current work are likely to be beneficially maintained as part of their clinical on-call portfolio, ${ }^{40}$ and which parts could be distributed among other members of the hospital team. This work should include data on fluctuations in work load, something that is likely to be required to define at which level overload will make a working pattern unstable and unsafe.

From these approaches, it might be possible to generate staffing patterns that are likely to be safe and those that are unlikely to be safe. This is something that is urgently required to assure quality care of patients in times of financial pressures, large-scale re-organisation of hospital services in many areas ${ }^{41}$ and rising healthcare needs of an increasingly frail patient population. ${ }^{42}$ The Royal College of Physicians is well placed to lead this work 
by using the expertise from the work force unit and the teams that have undertaken the work on Acute Care Tool Kits.

There is, however, some urgency in this situation as the Care Quality Commission will shortly announce its fundamental standards of care for healthcare in England and NICE will shortly specifically consider issues of medical staffing. Keogh, Berwick and Francis raise staffing as a crucial ingredient for safe care, yet our search seems to identify a significant gap in the available evidence to inform rational policy decisions.

\section{References}

1 Francis R. Report of the Mid Staffordshire NHS Foundation Trust Public Inquiry. London: The Stationery Office, 2013. www.midstaffspublicinquiry. com/report [Accessed 31 July 2014].

2 Keogh B. Review into the quality of care and treatment provided by 14 hospital trusts in England: overview report. London: NHS, 2013. www.nhs.uk/NHSEngland/bruce-keogh-review/Documents/ outcomes/keogh-review-final-report.pdf [Accessed 31 July 2014].

3 Department of Health. Berwick review into patient safety. London: DH, 2013. www.gov.uk/government/publications/berwickreview-into-patient-safety [Accessed 31 July 2014].

4 Royal College of Physicians. Position statement. Care of medical patients out of hours. London: RCP, 2010. www.rcplondon.ac.uk/ sites/default/files/rcp-position-statement-care-of-medical-patientsout-of-hours.pdf [Accessed 31 July 2014].

5 Dowdle R. Acute internal medicine and general internal medicine. In: Royal College of Physicians. Consultant physicians working with patients. London: RCP, 2013. www.rcplondon.ac.uk/sites/default/ files/acute_internal_medicine_and_general_internal_medicine_0. pdf [Accessed 31 July 2014].

6 Royal College of Physicians. Acute medical care: the right person, in the right setting - first time. Report of a working party. London: RCP, 2007. www.rcplondon.ac.uk/sites/default/files/documents/ acute_medical_care_final_for_web.pdf [Accessed 31 July 2014].

7 Aiken LH, Clarke SP, Sloane DM et al. Hospital nurse staffing and patient mortality, nurse burnout, and job dissatisfaction. JAMA 2002;288:1987-93.

8 Tourangeau AE, Doran DM, McGillis HL et al. Impact of hospital nursing care on 30-day mortality for acute medical patients. $J A d v$ Nurs 2007;57:32-44.

9 Rafferty AM, Clarke SP, Coles J et al. Outcomes of variation in hospital nurse staffing in English hospitals: cross-sectional analysis of survey data and discharge records. Int J Nurs Stud 2007;44:175-82.

10 Butler M, Collins R, Drennan J et al. Hospital nurse staffing models and patient and staff-related outcomes. Cochrane Database Syst Rev 2011:CD007019.

11 Jagsi R, Weinstein DF, Shapiro J et al. The Accreditation Council for Graduate Medical Education's limits on residents' work hours and patient safety. A study of resident experiences and perceptions before and after hours reductions. Arch Intern Med 2008;168:493-500.

12 Moonesinghe SR, Lowery J, Shahi $\mathrm{N}$ et al. Impact of reduction in working hours for doctors in training on postgraduate medical education and patients' outcomes: systematic review. BMJ 2011;342:d1580.

13 Zinner MJ, Fresichlag JA. Surgeons, sleep, and patient safety. JAMA 2013;310:1807-8.

14 Michtalik HJ, Pronovost PJ, Marsteller JA et al. Developing a model for attending physician workload and outcomes. JAMA Intern Med 2013;173:1026-8.

15 Royal College of Physicians. The medical registrar: empowering the unsung heroes of patient care. London: RCP, 2013. www.rcplondon. ac.uk/sites/default/files/future-medical-registrar.pdf [Accessed 31 July 2014].
16 Bell D, Lambourne A, Percival F et al. Consultant input in acute medical admissions and patient outcomes in hospitals in England: a multivariate analysis. PLOS ONE 2013;8:e61476.

17 Conway R, O'Riordan D, Silke B. Consultant volume, as an outcome determinant, in emergency medical admissions. QJM 2013;106:831-7.

18 Mueller SK, Call SA, McDonald FS et al. Impact of resident workload and handoff training on patient outcomes. Am J Med 2012;125:104-10.

19 Averbukh Y, Southern W. The impact of the number of admissions to inpatient medical teaching team on patient safety outcomes. J Grad Med Educ 2012;4:307-11.

20 Thanarajasingam U, McDonald FS, Halvorsen AJ et al. Service census caps and unit-based admissions: resident workload, conference attendance, duty hour compliance, and patient safety. Mayo Clin Proc 2012;87:320-7.

21 Ong M, Bostrom A, Vidyarthri A et al. House staff team workload and organization effects on patient outcomes in an academic general internal medicine inpatient service. Arch Intern Med 2007;167:47-52.

22 Haney EM, Nicolaidis C, Hunter A et al. Relationship between resident workload and self-perceived learning on inpatient medicine wards: a longitudinal study. BMC Med Educ 2006;6:35.

23 Herring R, Desai T, Caldwell G. Quality and safety at the point of care: how long should a ward round take? Clin Med 2011;11:20-2.

24 Stickrath C, Noble M, Prochazka A et al. Attending rounds in the current era: what is and is not happening. JAMA Intern Med 2013;173:1084-9.

25 Gill D, Gaunt R, Hamdulay S. No substitute for experience: do consultants that have been practising for longer lead faster post-take medical ward rounds? Acute Med 2013;12:141-5.

26 Tipping MD, Forth VE, Magill DB et al. Systematic review of time studies evaluating physicians in the hospital setting. J Hosp Med 2010;5:353-9.

27 Ghazanfar MN, Honoré PH, Nielsen TR et al. Hospital admission interviews are time-consuming with several interruptions. Dan Med J 2012;59:A4534.

28 Weigl M, Muller A, Vincent C et al. The association of workflow interruptions and hospital doctors' workload: a prospective observational study. BMJ Qual Saf 2012;21:399-407.

29 Coiera EW, Jayasuriya RA, Hardy J et al. Communication loads on clinical staff in the emergency department. Med J Aust 2002;176:415-8.

30 Laxmisan A, Hakimzada F, Sayan OR et al. The multitasking clinician: decision-making and cognitive demand during and after team handoffs in emergency care. Int J Med Inform 2007;76:801-11.

31 Innes GD, Stenstrom R, Grafstein E, Christenson JM. Prospective time study derivation of emergency physician workload predictors. CJEM 2005;7:299-308.

32 Anderson CK, Zaric GS, Dreyer JF et al. Physician workload and the Canadian Emergency Department Triage and Acuity Scale: the Predictors of Workload in the Emergency Room (POWER) Study. CJEM 2009;11:321-9.

33 Dubinsky I. Emergency physician workload modeling. CJEM 2012;14:212-7.

34 Royal College of Physicians. Hospital workforce: fit for the future. London: RCP, 2013. www.rcplondon.ac.uk/sites/default/files/ hospital-workforce-fit-for-the-future.pdf [Accessed 31 July 2014].

35 Chaponda M, Borra M, Beeching NJ et al. The value of the post-take ward round: are new working patterns compromising junior doctor education? Clin Med 2009;9:323-6.

36 Armstrong PA, White AL, Thakore S. Reduced productivity among junior trainees in the emergency department and the impact on senior clinicians. Emerg Med J 2010;27:97-9.

37 Armstrong PA, White AL, Thakore S. Senior house officers and foundation year doctors in emergency medicine: do they perform equally? A prospective observational study. Emerg Med J 2008;25:725-7. 
38 Le Jeune IR, Simmonds MJ, Poole L. Patient need at the heart of workforce planning: the use of supply and demand analysis in a large teaching hospital's acute medical unit. Clin Med 2012;12:312-6.

39 Dellit TH, Armas-Loughran BB, Bosl GJ et al. A method for assessing house staff workload as a function of length of stay. JAMA 2001;286:1023-4.

40 Royal College of Physicians. Acute care toolkit 8: the medical registrar on call. London:RCP, 2013. www.rcplondon.ac.uk/sites/ default/files/act8_registrars.pdf [Accessed 31 July 2014].

41 Future Hospital Commission. Future hospital: caring for medical patients. A report from the Future Hospital Commission to the Royal College of Physicians, 2013. London: RCP, 2013. www.rcplondon.ac. $\mathrm{uk} /$ sites/default/files/future-hospital-commission-report.pdf [Accessed 31 July 2014].
42 Royal College of Physicians. Acute care toolkit 3: acute medical care for frail older people. London: RCP, 2012. www.rcplondon. ac.uk/sites/default/files/acute-care-toolkit-3.pdf [Accessed 31 July 2014]

43 Michtalik HJ, Yeh H, Pronovost PJ, Brotman DJ. Impact of attending physician workload on patient care: a survey of hospitalists. JAMA Intern Med 2013;173:375-7.

Address for correspondence: Dr CP Subbe,

Ysbyty Gwynedd, Bangor LL57 2PH, UK.

Email: Christian.Subbe@Wales.NHS.uk

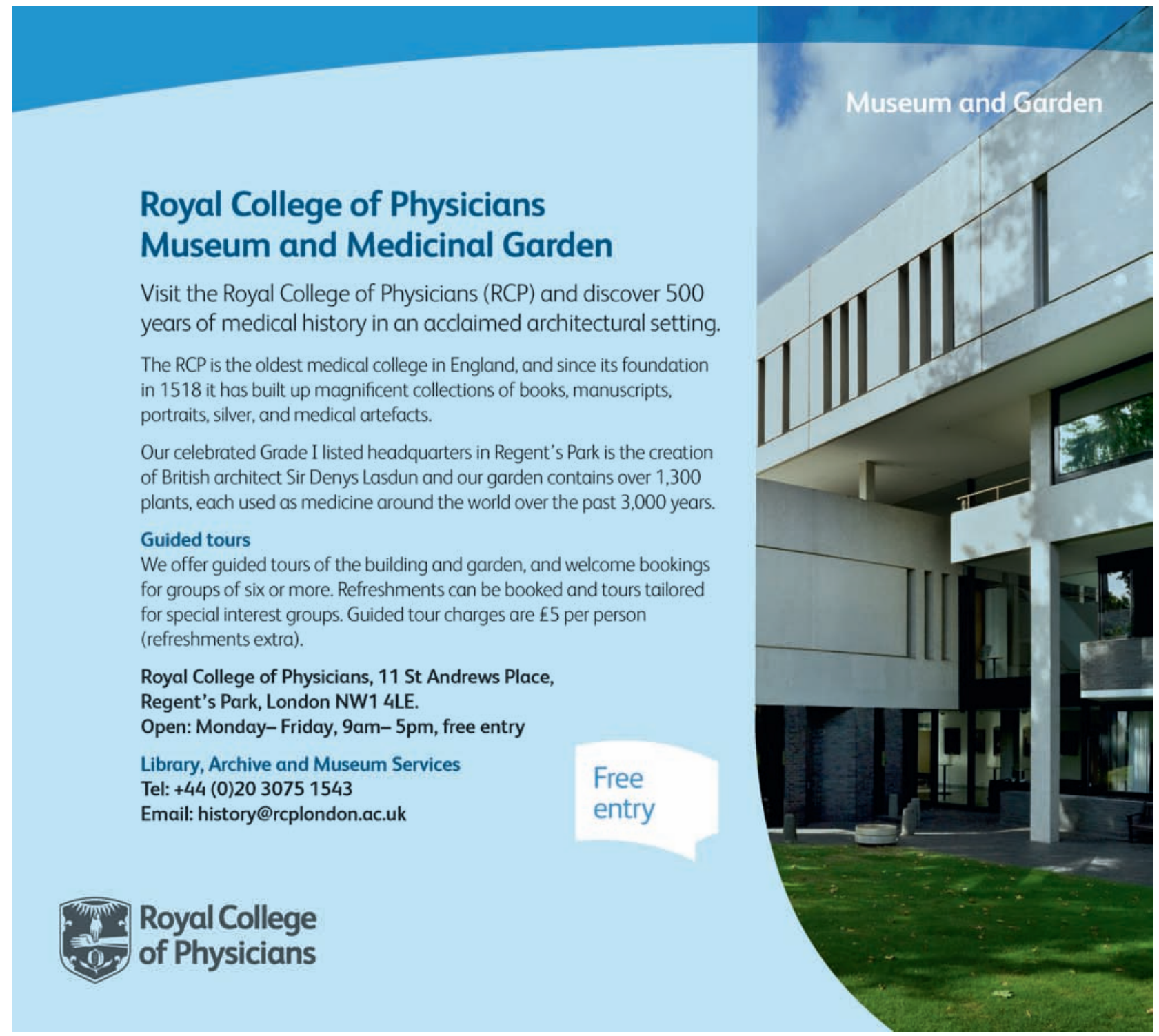

